\title{
QUEERING SPACE: LGBTQ* GAMING AS A FORM OF RESISTANCE AND COMMUNITY DEVELOPMENT
}

by

Samson G. Romero, BA, BSW, Ryerson University, 2015

\author{
An MRP \\ presented to Ryerson University \\ in partial fulfillment of the \\ requirements for the degree of \\ Master of Social Work \\ in the Program of \\ Social Work
}

Toronto, Ontario, Canada, 2017

(C) Samson G. Romero 2017 


\section{AUTHOR'S DECLARATION FOR ELECTRONIC SUBMISSION OF A MRP}

I hereby declare that I am the sole author of this MRP. This is a true copy of the MRP, including any required final revisions.

I authorize Ryerson University to lend this MRP to other institutions or individuals for the purpose of scholarly research

I further authorize Ryerson University to reproduce this MRP by photocopying or by other means, in total or in part, at the request of other institutions or individuals for the purpose of scholarly research.

I understand that my MRP may be made electronically available to the public. 


\author{
ABSTRACT \\ QUEERING SPACE: LGBTQ* GAMING AS A FORM OF RESISTANCE AND \\ COMMUNITY DEVELOPMENT \\ Master of Social Work, 2017 \\ Samson G. Romero \\ Program of Social Work, \\ Ryerson University
}

This paper will be looking at the influences of the creation of LGBTQ gaymer groups in the gaming world and within the LGBTQ communities itself. Through queering space and community development theory lenses, I look at how gaming that is dominantly viewed as being a straight, white, able bodied and a male space can be queered by the inclusion of LGBTQ players/gaymers. Using a critical ethnographic method through interviewing gaymer group leaders, I will explore how gaymer groups have had an impact on combating the harassment experienced by LGBTQ players/gaymers and how these groups have created their own communities that act as a form of queering up space and resistance to homophobia 


\section{ACKNOWLEDGEMENTS}

I express my warm thanks to my parents for their support as I enter this final phase of my academic education. Without their unconditional support, I would not have become the social worker that I am today.

I would also like to thank my supervisor Dr. Samantha Wehbi for her support and feedback, I would have not made it through this journey without her.

I would also like to thank two amazing people who have been there and have seen me in the worst and best during this process, Jason Truesdell and Paul Cadiente. I cannot imagine going through this without you two.

Finally, I want to thank the Toronto Gaymers for being the inspiration for this research. The work we do is important to our diverse membership and without this group I would not have the social support that keeps me grounded. 


\section{DEDICATION}

To all gaymers out there, please create meaningful friendships before you game, it's dangerous to game alone! 


\section{TABLE OF CONTENTS}

CHAPTER 1. INTRODUCTION \& THEORETICAL FRAMEWORK ......................... 1

Background and Positionality ............................................................................ 2

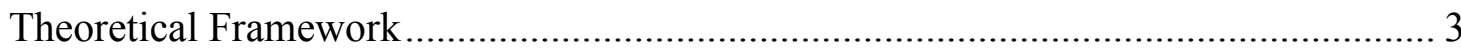

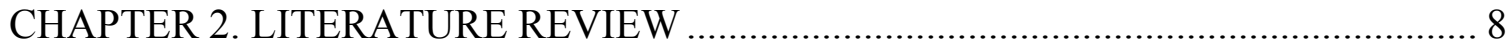

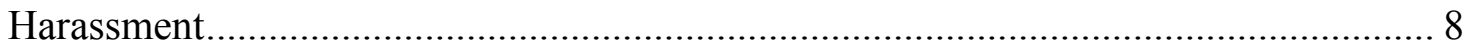

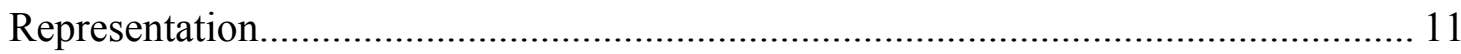

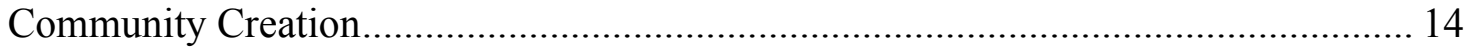

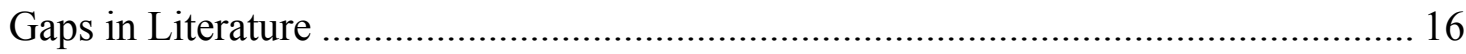

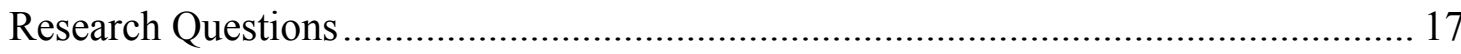

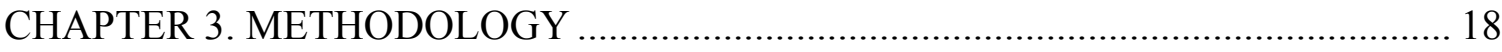

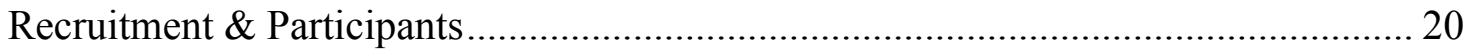

Data Collection \& Analysis ............................................................................... 22

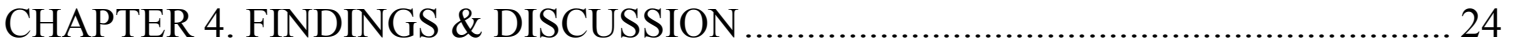

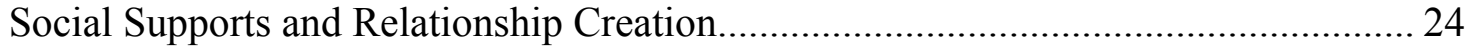

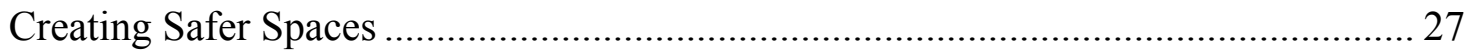

Politics and change within the gaming/geek community through queering space ....... 30

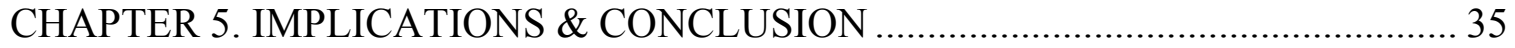

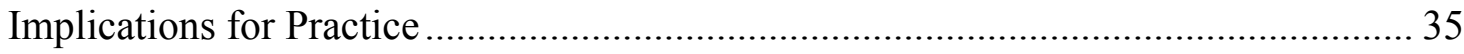

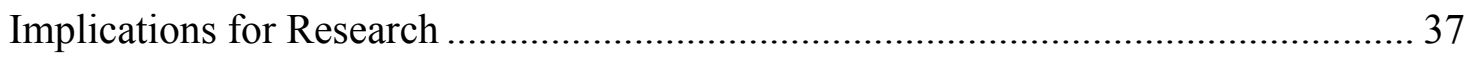

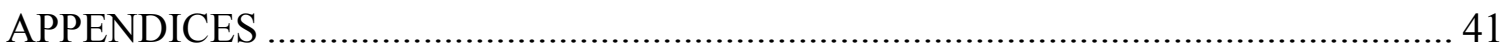

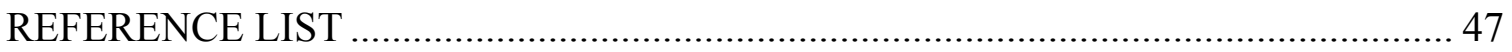




\section{LIST OF APPENDICES}

Appendix A - Recruitment Materials

Page 41

Appendix B - Interview Guide

Page 42

Appendix C - Consent Form

Page 43

Appendix D - REB Approval

Page 46 


\section{CHAPTER 1. INTRODUCTION \& THEORETICAL FRAMEWORK}

On-line communities have been growing since access to the internet has been made more available to a wider population (Hsiao \& Chiou, 2012). Likewise, gaming communities have also grown because of the internet and their gaming platforms have included online and multiplayer functions; this means that people can participate in gaming with others from all around the world without leaving their homes (Hsiao \& Chiou, 2012). However, this social interaction is still problematic because of an outdated idea that people who play video games (gamers) are identified as being male, white, able bodied and heterosexual, when in contrast that accounts for only less than $50 \%$ of gamers (Shaw, 2013). Unfortunately, this has led to gaming companies historically appealing to this assumed audience and has created a gaming environment that is hostile to those who do not fit the "standard" gamer. Those who have spoken out about problematic issues in gaming have often been ridiculed, harassed, and threatened (Pulos, 2013). Those mostly targeted are female and LGBTQ identified gamers who have spoken out against the harassment experienced or have tried to create inclusive spaces within these gaming environments.

Taking a community development approach, this research focuses on how LGBTQ players or gaymers have created their own spaces within the gaming world. Even though they are often met with resistance they have still endured this backlash and are active. Additionally, this paper looks at how the creation of queer space in the gaming world has been a form of resistance to homophobia and sexism. The creation of queer gaming space has created a community that is based on gaming and geeky culture and sexuality intertwined. 
For LGBTQ players or gaymers, whenever there is a creation of LGBTQ space either through representation or team creation in the games, it is often met with questioning of their validity (Braithwaite, 2014). LGBTQ players/gaymers must often hide their sexuality or have them silenced because, sexuality is deemed to be not part of game play. This has led to the creation of a toxic environment where heteronormativity is assumed and the insults thrown are either homophobic/transphobic or sexist in nature (Shaw, 2013). Games such as massively multiplayer online role-playing games (MMORPGs) where players must create an avatar and can enter romantic relationships either with other players or non-playable characters must sometimes choose a gender that is not reflective of them, thereby reinforcing heteronormativity.

Thus, examining the experiences of LGBTQ players/gaymers, provides an example of an oppressed community that is experiencing marginalization and how they organize themselves to create their own communities to counter this oppression. These gaymer communities are an example of community development and in a sense, represent a resistance to homophobia (Evans \& Janish, 2015). Social work is linked with community development and creation; specifically, anti-oppression social work discusses the importance of communities working towards fighting the oppression they experience. The development of gaymer communities in the gaming world are examples of resistance (Lessard, 2013); just by existing, they are altering a space that is assumed to be for a dominant group into something of their own.

\section{Background and Positionality}

As the primary researcher for this paper my interest in gaymer groups comes from the work I have done with the Toronto Gaymers group as the Outreach and Community Development Manager. In that role, I had the privilege to work with other gaymer groups from 
around the world and to see the impact their groups have had. In addition, I do identify with the "gaymer" identity as an avid video game and board game player so I do come into this research as an insider to the gaymer and gaming community.

My involvement with the Toronto Gaymers has influenced me in conducting this research because of the impacts I have observed with the group. I have noticed that the group is growing yearly and that many new members do join as some leave. This shows me that there is need for this type of group. Secondly, members becoming more active through volunteering or participating through events reveals that members are invested and are here for the continuation of Toronto Gaymers for years to come. Further, as a social worker, I have used my skills in my position with Toronto Gaymers to help them develop the organization to be efficient and develop a foundational structure.

\section{Theoretical Framework}

My theoretical background for this research comes from Henri Lefebvre's (2009) concept of production of space and the incorporation of queer theory in relation to geography. Hence, I am using queer space theory as a foundation for this research. As I stated earlier, gaming is linked to social space because of a creation of a form of social space, although it is in cyber format. Cyberspace or virtual space is social space because of the interaction among peoples through this medium. Gamers can create friendships and have social engagement with others through this medium because of interactions through chat and or voice and video interactions (Shaw, 2012). As noted earlier, the main group of people that is seen to be the dominant group in gaming is assumed to be white, male, able bodied and heterosexual (Shaw, 2012). With the dominant group being the "owners" of the space, it is tailored to them. This can be seen in 
gaming narratives such as saving the female princess as a male hero. Many games including those that allow customization of avatars have the default protagonist as being male and white (Shaw, 2012). This again is just reflection of who is perceived to be in this space and thus normalizing who it belongs too.

Lefebvre (2009), discusses the idea of space through a Marxist lens of a means of production. A concept that he brings up is of representational space, that is the space that is directly lived through its associated images and symbols, the space of the inhabitants (p.39). In relation to my research gaming culture has many symbols that represent it such the idea of levels with players, the higher the level the more power you have. For example, in some MMORPG games having certain rare items represents a player's advanced skill or ability to obtain the items from a special event. Additionally, the higher the level you are the more you can be viewed as an experienced player and as a threat. All of these are some examples of symbols of culture in gaming.

Additionally, the concept of representations of space describes what people in a society identify with, what is lived, and what is perceived with what is conceived (Lefebvre, 2009, p.38). It is the idea that people see a space and create it into their own. In relation to gaming and the LGBTQ communities this concept is relevant. Gaming communities have turned gaming spaces into worlds where people play and socialize together, this can be seen in MMORPGS and in realtime strategy games (RTS) games. These communities have created their own culture in the space through community events within the games as seen in MMORPGS and in competitive gaming in RTS where a game like League of Legends has a sold-out finals match in a sports' stadium (McNeil, 2016). For LGBTQ communities, space has the history of resistance to 
homophobia and community creation such as Gay and Lesbian bar culture (Lessard, 2013), that has created a "safer" space for LGBTQ people to meet others. The creation of these bars has created an LGBTQ geographical community around it. Both communities are creating a space and culture that is unique and caters to their communities' needs.

When we queer space, it means changing a space that is perceived to be for a dominant group to cater to another group (McCaffrey, 2013). The example of straight bars catering to gays and lesbians at certain times is an example of queering space (McCaffrey, 2013). For the gaming world, this queer space involves creating LGBTQ specific groups, in the case of MMORPGs that means creating queer teams/guilds. Another way to queer space in gaming is through creating LGBTQ specific groups such as gaymer groups, this term resists heteronormative discourse- the word "gaymer" itself is a play on the word "gamer." Changing and creating a new gaming identity is an example of queering. This is another form of political action that disrupts heteronormativity through linguistics (Lewis, 2013).

Furthermore, community development theory also plays a role within this research, Chaskin (2013) notes that the social dimension of community relies on the relationship among the people within it and their relation to a collective shared identity, norms, and interactions (p.107). He also states that these interactions are tied to the concept of space (p.107). He furthers elaborates that communities have some form of spatial area that connects the individuals within the community. In relation to this research, the space here is the virtual space in the gaming world. It can also include spaces at gaming conventions. These spaces are meant to be reflections of a community and are meant to reflect the commonality of a shared identity. For this purpose, it is the idea of gaming that fulfils this role (p.107). 
Gaming LGBTQ groups or gaymer groups are an example according Chaskin (2013) of a community as space and place (p.110). This means that communities are linked through an organized space (p.110). For gaymer groups, individuals or members are linked through the space taken up in the gaming world; this includes the creation of guilds in a MMORPGs that are LGBTQ specific and also through LGBTQ groups organizing online through a specific game such a first-person shooter. In addition, the localization of gaming interests within a geographic area can be viewed similarly. The "cognitive map" of an individual member of a gaymer group in relation to the group itself would be one that links their membership to a specific game or to a gaymer group within their local area. The need or want to be part of a gaymer group relates to safety and to absence of fear of being rejected because of their sexuality; gaymer groups are perceived to be a community or space that fulfills this need. The boundaries that Chaskin (2013) says are part of this theory in relation to gaymer groups is the ability to be oneself in the games and having the feelings of knowing that those part of the group will share a similar of view of not being judged or harassed.

I stated earlier that community is also about interaction, identity, and function; according to Chaskin (2013) this means that communities are created through the relationships among the individual members through common identity, shared norms, and concrete interactions and exchanges (p.107). These relationships are said to be loosely tied to space but more involved with the intimate relationship that are developed; in relation to LGBTQ gaming this involves a person's sexual identity, and possibly gender identity as well. It will also include a person's interest in gaming (either video or board games or both). 
Although, identity and common interest can create a community it does require relationship building; in relation to gaming, this is possible because of the advances of gaming technology and the inclusion of the internet. MMORPGS require players to interact with each other in real time through either chat or the usage of voice communication in game, this has aided in people interacting with each other; and because MMORPGS do take massive amounts of time to play and players can develop social relationships during this time. These relationships can develop because players do spend time with each other and can get to know each other on various social levels mostly through questing. An online community is created because of this interaction in a virtual space and having common interests, which is the game-play itself.

With this understanding of community and its relation to the impact it has on social space we can see how queer space theory and theories around community are relevant to LGBTQ gaming. Virtual spaces have to be seen similarly to non-virtual spaces; in this sense, games have helped develop a new form of communities that can exist online and further develop off line through the common interest of gaming and the social aspect that has evolved from gaming technology advances. The next chapter will look at current research into gaming, identity and community creation. It is through this literature review that we can better grasp this idea of an LGBTQ community being created in spaces that again are viewed to not represent or reflect them. 


\section{CHAPTER 2. LITERATURE REVIEW}

My literature review was conducted through researching various journals of sociology, media studies, women studies journals' and community social work journals to grasp a better understanding of research on the topic of LGBTQ gaming. Some of the terms that were searched include: LGBTQ in gaming, representation in gaming and LGBTQ online communities. The literature review produced three main themes. The first theme focuses on the harassment of LGBTQ identified players and non-males. The second theme looks at LGBTQ and representation. The third theme explores the need for community creation within the gaming world. All three of these themes have led to the development of two research questions, discussed at the end of this chapter.

\section{Harassment}

Being a woman or openly queer identified in gaming has resulted in experiencing harassment either directly or indirectly. Pulos's (2013) study revealed that many heterosexual players had a negative view when an LGBTQ guild is presented in the online game World of Warcraft forums (p.86). The author wrote of the microaggressions of homophobia through comments such as "sexuality has no place in the games or that this about ability" (p.86); these comments are common and are a form of silencing. The opinion of not wanting an LGBTQ guild in World of Warcraft, shows how players in online games are upset when a space they see through their lens as being heteronormative has a bit of queering done to it. Space is political, as noted in my theoretical framework; Lefebvre (1991) suggests that the idea of representation of space is not in the physical sense but is ideological. Gaming space ideology would assume that 
everything is heteronormative and binary, but the inclusion of queer space challenges this assumption.

Pulos (2013) notes that homophobic comments from other players on the message boards that were opposed to an LGBTQ guild in World of Warcraft reinforce heteronormativity and push gaymers and women to the fringes of the other (p.87). This is a form of harassment of being pushed out and erasure to ensure that dominate discourse of heteronormativity is being kept. He advocates that companies who develop and run these games keep and protect LGBTQ guilds because they are providing safer spaces for LGBTQ players (p.90). Pulos's (2013) study did have limitations; he does acknowledge that gaming developers and companies do have to act when harassment occurs in their virtual worlds and that they cannot remain silent (p.78). In addition, the author suggests that LGBTQ people create their own games to counter heteronormativity in narratives and discourses (p.90).

Salter and Blodgett (2012) further show how challenging sexism brings out harassment for those who call out this oppressive behavior. Their case study about the situation at the video game expo, Penny Arcade (PAX), provides an illustration: when sexist behavior around rape culture at PAX was called out by female blogger Courtney Stanton online, she was bombarded and harassed online mostly by males (p.408). Salter and Blodgett (2012), rely on an analysis of "hypermasculinity" to explain the huge backlash against mostly female gamers who felt uneasy about the incident (p.410). Hypermasculinity reinforces this idea that women are the ones a fault and that gaming is a space for men; and instead of learning why sexist behavior is harmful, men defend it (p.413). 
This behavior is further seen in Andrea Braithwaite's (2014) critical discourse analysis of the difference of a non-playable character's (a character in game that a player cannot play but interacts with in order to progress the game) responses as they varied due to gender or a player's avatars. She noticed that the dialogue was different when the player chooses a female avatar when compared to a male (Braithwaite, 2014). The female avatar received a flirtatious response from the non-playable characters while the male avatars were received with neutral responses (Braithwaite, 2014). When she voiced her concerns about the sexist dialogue from the nonplayable characters, she was met with negative resistance. This response occurred in official forums where she was told that she was being a "feminist killjoy" and told to "get over it" (p.708). She was challenging a male-dominated space; sexist and oppressive reactions occurred to try to silence her. This response further shows how challenging sexist behaviour reinforces heteronormativity and toxic masculinity.

Kaye and Pennington (2016), also conducted a study about the impact that negative stereotyping of female gamers had on their gameplay. Her study showed a negative correlation when the group of female gamers in the controlled group began to underperform because they were exposed to negative messaging (p. 206). The females who did not have negative stereotype messaging performed better (p.206). Linking this with harassment from the previous studies shows how creating a sexist and homophobic environment can be harmful.

In the above-discussed cases, women and LGBTQ gamers were met with resistance because of hypermasculinity and challenging of space that was viewed as being the ownership of cis-males. Teng et al.'s (2010) study further emphasized this when they looked at online gaming misbehaviors and causes of anger in gamers, although a limitation of this study was looking at 
both male and females. The authors found that players used much profanity when gameplay was interrupted (p.353). Linking the harassment of women and LGBTQ players for calling out sexism and homophobia from other players would be seen as an interruption in gameplay and would trigger a negative response. It would also reveal learned and hidden sexist and homophobic attitudes that are released when space is challenged.

Resistance to homophobia and sexism in gaming was also discussed in Evan Lauteria's article (2012). Lauteria looks at how modding, the ability to alter a game's original program to change narratives, is a form of queer resistance. Modding allows players to re-program narratives that are formerly heterosexual into alternatives such as homosexuality, bisexuality, asexuality, etc. The modds give power to the player and are not restricted by the original game developer's views. This form of resistance shows how gaymers and women can empower themselves by learning the mechanics of games. Having the ability to code and then re-modify a game to reflect their own lives and narratives is a method of resisting and countering oppressive actions in the games directly.

Although sexism and homophobia can be viewed separately, the studies have shown that they are linked. A common thread of harassment that is seen in the literature revolves around either a player's assumed gender or sexuality (Shaw, 2009). Thus, the relationship between sexist and homophobic harassment is often intertwined. Further, players do have multiple and intersecting identities. Combating harassment is a political act because it is about a marginalized group challenging a dominant group who think they have ownership of space.

\section{Representation}

Representation is an important theme in the literature; specifically, the importance of 
gaming narratives reflecting not just one group of people but a diversity of other groups. Shaw (2012), studied how players identify as "gamers." Shaw (2012) conducted an ethnographic study using queer theory as her lens. The results of the study showed that many women and LGBTQ players would not identify as "gamers" because many viewed gaming as a "guilty pleasure" (p.38). Also, Shaw looked at how game companies purposely exclude women and LGBTQ players because of the assumption that their primary game players are heterosexual, white, ablebodied, cis-males; this has disproven by studies done on gaming demographics (p.29). Exclusion of LGBTQ gamers and women is an example of erasing people, and it sends a message that gaming is only for certain people that fit into a dominant discourse of white supremacy and patriarchy. It explains why many women and LGBTQ gamers do not identify as "gamers" because of this exclusion.

Shaw's (2012) ethnographic research was useful in seeing how identities are created and how people associate or dissociate from belonging to these identities. Her sample size was more diverse than other studies that I have reviewed and linking the intersecting identities gave the research more depth. Shaw does note that some of her limitations are around seeing gaming as a medium of communication and socialization instead of through marketability (p.40). The validation of games comes in seeing them as more than just a toy but as a way people communicate with each other, as well as games being another form of storytelling. There is a political purpose to gaming in part due to its ability to link people from all over the world and create community.

Eklund's (2011) study discusses female World of Warcraft (WoW) players' reasons for creating game avatars that reflected them based on their gender identity (p.329). All participants 
chose female avatars but did not disclose their real-world gender because of the fear it would impact their experiences in the game from other players (p.332) who may treat them differently. Sexist harassment was a reason for not disclosing their real-world gender identification. This concern was also reflected in Lee's study (2014) that looked at Black gamers who created avatars that looked white, instead of reflecting their real-world racial identities (p. 195). Their reason was due to limitations in choices and also fear of harassment as well. Additionally, Cruea and Park (2011) conducted a study that looked at gender representation in games and how this further emphasized that gaming is primarily male dominated because of reinforcement of outdated gender roles and sexist imagery (p.48). Through testing how hypersexualized images in games can impact the amount either gender spend playing games, their results have shown that this imagery did have an influence on the amount of gaming play (p.55).

Schmieder's (2009) study on sexuality in WoW also revealed that if a player's avatar does not match their gender in the real world, there is immediate discomfort (p.13). The reasons for this discomfort is that there is a view that the virtual world and the real world are supposed to be reflective of each other (p.14). However, looking at previous studies, it is ironic that a player who identifies as LGBTQ or as a woman may be harassed for revealing their identity; especially if they choose to challenge oppressive behavior in the games.

The studies in this theme from the literature show that representation is crucial in challenging and creating safer spaces for women and LGBTQ game players. Representation is political because it makes a statement that space is dominated by a group that has belief that it is the natural owners of the space. Space is political even in the virtual realm. Most of the resistance to claiming space in games such as World of Warcraft is a backlash and reaffirmation 
of patriarchy and white supremacy. The idea of hyper masculinity that was brought up in the previous section further supports that gaming space is a "white boys' club," although again research has shown that this is not the reality. Representation either through women and LGBTQ gamers becoming visible, through more diversity in game developers, and through the prodding of game companies to look beyond their profits and into social impacts such as community creation will spur change to happen.

\section{Community Creation}

The final theme in my review of the literature was the idea of community development or creation through gaming. Hussain (2014) conducted a study that looked at the reasons why people play online games. His research has shown that gamers do learn social interaction skills through playing together (p. 51). Games such as WoW and first-person shooter (FPS) games are team driven and require people to communicate to work together and create an obligation to play because others are relying on you (p.51). The internet has changed video games from isolated consoles and computers to a network that links people from all over the world. Also, games like WoW have no real end game and thus can go on indefinitely (p.48); this creates a space where people can just interact with each other, with no pressure to finish the game.

Ghuman and Griffith (2012) looked at motivation of players/gamers to play their games through different genres. Their research has looked at role-playing games (RPG), first person shooter (FPS) and real-time strategy games (RTS). They noticed that communities were created but this varied from genre to genre; for example, RPG and FPS gamers were more inclined to meet up socially outside of the games in a social setting; whereas RTS players would meeting up to play game in the same room (p.26). Further, the study noted that FPS would have mostly 
male players while RPG would be female dominated (p.24). However, FPS players would be more likely to be friends outside of the games, compared to RPG and RTS players (p.24). Ghuman and Griffith's study does show that a community is being created though video games, although the word "community" is never stated directly. The results indicate people interacting with each other socially in video games; indeed, the games themselves are often used a medium to meet others and to create a common interest.

Based on the literature, social interaction and community creation are important reasons that spur gamers to continue to play video games online. For LGBTQ players, finding a community to belong to is also important. Hanckel and Morris (2013) conducted a study on the importance of online communities helping LGBTQ youth and challenging heteronormativity. The authors discussed that many LGBTQ youth do experience isolation because of their sexuality (p. 878). However, though online communities many of the LGBTQ youth could find information and meet others and create networks (p. 879). Also, the online communities created were able to help politicize the youth to act; in this study, the political issues were for equal rights and same-sex marriage legalization (p. 882). If it weren't for the online community, many of these youths would still be isolated. Linking this study with the gaming studies shows the importance of online communities for people. Many of the gamer studies do show that games are just a medium to socialize through common interests. However, that interest may be the only sort of social interaction many of the gamers and even LGBTQ people will have.

Coalition building is another aspect of community building that LGBTQ gamers can engage in when combating oppression. Beth and Janish's (2016) article, discusses how the harassment of LGBTQ gamers and women created a coalition to confront and challenge the 
harassment. During the \#gamergate incident, male gamers harassed many females identified game developers, feminist gaming scholars and those who spoke of social justice in games (p.127). A coalition was struck by community groups that have been impacted by harassment in gaming. The hashtag \#ineeddiversegames was created as counter to the hashtag \#gamergate. This form of online resistance provided a means for oppressed groups to fight back. Further, \#ineeddiversegames acknowledges intersectionalities and diversity of LGBTQ communities, fighting again against binary thinking (p.141).

\section{Gaps in Literature}

Upon reviewing the literature, I noted a gap regarding gaymer experiences. Studies were often done around gender linked with sexuality, but there were few specific peer-reviewed studies around sexuality and gaming. Shaw (2012) and Pulos (2008) were the only authors who explicitly put LGBTQ identities and gaming in their research. In addition, more research is needed on other game genres, Massive Multiplayer Role Playing Games (MMRPGs) seem to be the primary focus, whereas there is not much research on FPS or RTs games. Also, the studies of these games need to be examined through the lens of queer theory. Most of the LGBTQ focus on gaming studies was through the genre of MMPRGs; specifically, World of Warcraft, other genres such as mobile games, Esport real time strategy games such as DOTA2, first person shooter games, and even board game groups have little to no literature on them. These games do create communities, and there is an LGBTQ presence in all of them. Expansion of research to include these games would give more insight to gaymers' realities and learn about alternate forms of community development.

More research is also needed on how LGBTQ players are resisting harassment through 
LGBTQ game developers creating their own games and expressing their narratives. Queer space is being created in the virtual world. The former website gaygamer.net was essential in bringing together many LGBTQ gamers and the creation of the Rough Trade Gaming Community, an LGBTQ-focused MMORPG website that organizes LGBTQ players in other MMORPG such as Final Fantasy Online. Also, the creation of Gaymer X, an LGBTQ gaming convention that does try to be inclusive of people's intersecting identities, was created because of the need of safer LGBTQ spaces. These efforts would be important to study as examples of resistance and building community. However, there are also no studies about local gaymer groups that have been created from members who saw a need for them. In Canada's three biggest cities there are three gaymer groups that have hundreds of members and provide safer spaces through social meet ups, but none have been studied, and especially through a queer space lens.

\section{Research Questions}

Based on the gaps in the literature as well as my chosen theoretical framework, I developed two research questions. First, how are the creation of gaymer groups and organizations a form of resistance to heteronormativity in gaming world spaces? Second, what impact have queer gaming spaces contributed to influencing changes in gaming culture and community building among LGBTQ players/gaymers? Through both questions, I hope to learn how these examples of resisting heteronormativity can enhance social work efforts in this area of practice and how they can support the creation of community in its multiple forms. 


\section{CHAPTER 3. METHODOLOGY}

This study relies on critical ethnography as a methodology. The usage of critical methodology for this research acknowledges that as a researcher I have a position power within this study. I acknowledge that I am a gaymer leader and thus I am also an insider as I conduct this research. Additionally, critical ethnography incorporates many ideas that reflect my stance as the researcher. The first relevant idea is "openness and transparency" which means for this study that I will explain the truthfully the purpose of my research to my participants and any benefit that they or their group may receive from it (Madison, 2005). There has not been any specific research about gaymer groups and I did mention this to my participants; this research aims to begin the discussion and possibly critical reflections on the impact gaymer groups or LGBTQ gaming organizations are having on combating homophobic harassment. Additionally, gaymer groups have created communities in spaces that are viewed as not queer nor queer friendly. Being open about my literature review and my own professional gains (attaining the MSW) ensures that transparency exists about the aims of the study.

Moreover, critical ethnography is consistent with my theoretical framework. My questions are about who's attending and benefiting from these gamer groups and who is left out. Being critical of the group composition is also important and may help these groups as they work to be more inclusive. LGBTQ communities are diverse and only a certain group or community is reflected in this study (please see limitations later in this MRP). The findings should not be taken as an accurate reflection of reality but instead viewed as a beginning of road map if further studies are to be conducted. Indeed, Madison (2005), warns of the negative impact that research can have on a community and that as researchers we should be cautious about this (p.116). 
Additionally, as anti-oppressive social workers we should be always self-reflective or reflexive (Fook, 2012, p. 49); this mean being aware that certain groups that are within LGBTQ communities maybe left out of the dialogue. As researchers, it is important to ask about this and this may be uncomfortable, however if we do not ask who is left out, this is a disservice to antioppression and critical queer theory research.

Additionally, my justification for using critical ethnography for this research links back to this paper's theoretical framework, which is that of queering space. Lessard (2013) discusses the importance of space within ethnography and that this concept is fundamentally linked to studying communities (p.260). Within this space, my positioning is important to acknowledge because it does show my influence within both the LGBTQ and gaming communities. As a gaymer leader in my city I have knowledge and connections to other gaymer groups throughout North America. This position is important to acknowledge because I have relied on my membership in this community to access other leaders with whom I have a professional connection.

Using critical ethnography also aligns with my practice of social work, which comes from anti-oppressive and decolonizing lenses. Critical ethnography according to Madison (2005), does bring up notions of mindfulness and to be self-reflexive and self-critical of our values and perspectives when conducting research (p.124). These values are important to me as a researcher because the research I am conducting does have a direct impact on a community within which I am an insider. It is important that the research is done so it is beneficial for the community in the end and not just for my own personal gain. 


\section{Recruitment \& Participants}

Recruitment for this research targeted gaymer leaders or main organizers who are at least 18 years of age and are part of a gaming group that is LGBTQ specific and is currently active. This focus was so that I could interview key stakeholders of the LGBTQ gaming community who are seen as doing frontline work. My rationale behind this is that these key community stakeholders would have knowledge about their respective groups and could share how their groups function and the impact these communities may have had. In keeping with critical ethnography, this is done to reduce negative harm and to ensure accountability (Madison, 2005). From a quick survey on the various gaymer group from web searches, I discovered that there were several LGBTQ or Gaymer groups in existence throughout the world. A bulk of them are located within North America and out of these, three are located within Canada. I outreached to LGBTQ gaymer leaders or main organizers that were part of a Facebook group centered around LGBTQ gaymer organizers and leaders.

Specifically, I recruited through social media and community forums that are dedicated to LGBTQ gaming such as the LGBTQ Video archive page (https://gbtqgamearchive.com/) and on various social media sources (please see Appendix A for recruitment material). The LGBTQ gamer archives webpage is run by one of the leaders of LGBTQ gaming research, Adrienne Shaw, and is updated frequently. It is a valuable resource that is developed from the ground up. Social media is another area where recruitment was conducted because of the ease of organizing groups through this source; these groups can closed or private, which allows gatekeeping of membership to ensure safety for the members. As noted earlier, research or recruitment with gaming that involves studying women and LGBTQ people has often been met with some 
resistance in the form of silencing and harassment. Thus, the ability to gatekeep who is part of a group is important so that LGBTQ gaming groups can have safer space. For this research and to reduce this risk of silencing or harassment, I did not post anything on public social media platforms. Instead, I relied on recruiting participants by directly emailing them. The purpose of directly asking groups and not through public posting is also to reduce the possible harassment I may experience.

Through my outreach efforts described above, I recruited three participants identified as being "leaders" or "organizers" of their respective groups. Below is a brief description of the three participants identified by pseudonym:

- Peter: An organizer for a gaymer group located in a large city that organizes various social events and outreach in the communities and in the greater region.

- Tom: An organizer for a gaymer group located in a large city, that organizes various social events. The group has a presence in local communities and online.

- Orion: An organizer of a LGBTQ group that resides mostly online but has set meet up dates. The membership span across various borders.

It is important to note that the interviewees identified as cis-gendered perspective and mainly identified as being gay. All the participants have been involved with their groups for over three years and have a vast knowledge of the workings of their groups.

The study does have several limitations, the first being that of time and feasibility constraints; with the limited amount of time I was only able to recruit three participants for this study. To have a better understanding of gaymer groups and their impacts I would recommend expanding participation to at least 6-8 more gaymer leaders/organizers to have a wider grasp of narratives and knowledge. Moreover, gaymer leaders'/organizers' viewpoints may not necessarily reflect what members of their groups feel or how they see the group as being 
supportive or not. Further, if I were to re-do this study I would also consider doing a mixed method study that would add quantitative data from gaymer group members. This data would enhance the narrative with statistics and would aid in giving members input on the impact gaymer groups have had on them.

\section{Data Collection \& Analysis}

I relied on interviews (one in-person and two by Skype) when conducting this research so I can hear narrative from the key stakeholders about their experiences (please see Appendix B for interview guide). Open ended questions allowed me to listen and to learn from the participants because their experience and time are gifts to advancing knowledge about the issues addressed in this study. The concept of knowledge as a gift comes from an Indigenous world view which is consistent with my decolonizing lenses on social work (Baskin, 2011, p.229). The gaymer leaders' knowledge will benefit me and I do have to ensure that there will be some benefit to the gaymer communities in general from this research. The interview is a form of allowing me to sit beside the participant, to listen and reduce power dynamics that give me a power over relationship instead of a power with.

When conducting interviews, it was important that I ensure confidentiality of my participants; the primary reason is that the LGBTQ gaming community is small and it can be easy to identify who the participants are. Madison (2005) advocates for confidentiality to avoid negative impact and to ensure that the relationship between the interview and participants and community is based on trust that the narratives will not be misused and that those telling their stories will be protected (p.142). In addition to being an important part of research ethics in general, confidentiality is important to this research because I did want the participants to be 
open and honest about their narratives; and this can only be achieved through ensuring confidentiality. Thus, when people are reading my research they cannot identify who the participants are (Please see consent form in Appendix C).

In terms of data analysis, I transcribed the interviews verbatim and relied on thematic analysis. I looked at the common themes that were spoken during the interview. This was done to see the similarities and the differences between the participants' ideas. Through this analysis, I attempted to answer the research questions. My focus was on answering my research question focusing specifically on how gaming can create or shape queer space that resists heteronormativity and create community. In the remainder of this MRP, I discuss the findings of my interviews and provide a discussion of implications for social work. 


\section{CHAPTER 4. FINDINGS \& DISCUSSION}

The interviews conducted in this study revealed the main finding that gaymer groups offer important social supports for their members. Additionally, advocacy was found in groups that had wider membership that extended beyond geographies; whereas the geographicallyfocused groups were more linked to was impacting their members locally where they reside. Finally, the idea of creating safer space was mentioned often from all their participants although this did vary, but all had the goal of creating these spaces so members can be themselves without judgement.

\section{Social Supports and Relationship Creation}

The creation of social supports was brought up in all three interviews. The development of friendships and possibly even romantic relationships was cited as a primary reason for people joining gaymer groups. An example of the creation of social supports can be seen from Tom, who notices the friendship that is created from the group and the support that can come from it. He says, "our members are constantly smiling over the months and years and strong friendship arise. Unfortunately, people go through tragedy but then they have these friendships that help them get through that". Similarly, Orion says that friendship development is a reason why people come back to the group: "friendships online, via a game, and I think that having this secondary way of, sort of, cementing the relationship and reaffirming that friendship". Additionally, this was also shared by Peter who says that members "successfully make a lot of friendships, there are at times relationships that come out of that. Although relationships aren't a focus of the group, more about making friends". 
All three leaders stated that friendship creation is one of the main reasons why members choose to return to their groups. I stated earlier that community building was a theme among gaymers/LGBTQ players and all three of the interviewees note that their groups have members return because of the friendships created. Having friends, especially ones that share similar interests is important in dissolving feelings of isolation and also in developing a social support system during crisis. As Tom noted, the friendships created are beneficial to people especially when an individual experiences life changing events such as death or other life stressors. Social supports such as friends can provide emotional care needed when these situations arise. This is especially important in this context with issues around dealing with one's sexuality or gender identity; friendships can mitigate feelings of isolation.

Linking this back to the literature and community social work theory, the relationship built are foundations in community creation (Chaswick, 2013). Without these relationships, communities would not form. They are forms of networking (Chaswick, 2013) that give a reason for people to come together. Using gaming as medium to facilitate these relationships, friendships are created and are now utilized a social support for person. In the LGBTQ communities, isolation can occur and sharing a similar sexual orientation may not be enough to foster a social relationship; gaming can create these bridges in developing a friendship beyond sexuality alone. As Tom notes about his group's organized activities:

...it's anything or everything (we) will do picnics in the park or we will do board game meetups where members can come and play games with each and people can organize events privately or go see a movie or play a video game through the internet. Or just hang out and get to know each other. 
With the creation of these friendships, there is also the creation of gaymer communities. As noted earlier, many of the members of the gaymer groups often return because they have made new friends. With these new friendships, gaymer communities develop; and a sense of ownership can develop where the membership understands the importance of keeping these groups active.

With the creation of social supports in gaymer groups, the impact has been positive for many of the members' mental health needs. As noted by Tom in relation to mental health support:

We have a lot members that who are economically speaking in dire straits or have various mental health issues; such as severe anxiety or depression and bipolar disorder which are very common in our group. And the safe space we provide allows them a social outlet to develop in order to strengthen their own circle and own friendships. Over the years, I've seen people who battle depression have a smile on their face while they are at our events. Additionally, Tom also says, "For some of our shut-in members it allows them the ability to leave the house but knowing they are going somewhere where they don't have to put their walls up". Seeing a gaymer group provide mental health support is interesting because we typically assume mental health needs to be supported by social or health professionals; however, these findings note the importance of social supports that gaymer groups can have on a person's mental health. Tom's observations about his members who are experiencing mental health needs shows that gaming is a method that these members use to cope; additionally, the existence of the gaymer group as a safe space for them to be open about their mental health along with their 
sexuality and gender identity shows the importance of gaymer groups offering this space of support.

In short, the social supports that gaymer groups have created show the importance of their existence. As I stated earlier, these social supports that are being built help LGBTQ players/gaymers in addressing or dealing with homophobia or other oppressions they may be experiencing in the gaming world. Additionally, the social supports created can further help in coping if people are experiencing mental health issues. Relating this back to Chaswick (2013), this gaymer community is a social system where members are able to obtain goods and services (p109). In this situation, it would be the social supports or friendships that are developed from meeting at gaymer groups, which help in developing a gaymer community because the members involved realize the importance of coming together through their hobby and their sexuality or gender identity. Additionally, Chaswick (2013), brings in the community as a political unit (p.113); for gaymers, this is the organizing of the group itself. Existing and creating these safer spaces is a political action: the action of queering space within gaming and challenging heteronormativity.

\section{Creating Safer Spaces}

Another common theme that emerges from all three interviews was the notion of creating safer spaces for members of gaymer groups. All three participants mentioned that creating safe spaces was important because many members felt unsafe in playing some games, especially

those online because of homophobia and harassment. Orion mentioned that his gaming group space allows people to be themselves. He says, “...we also encourage or at least allow space for people to discuss their sexual selves in some capacity." He further echoes this by saying, 
But at the end of the day, our big -- our big purpose - our only purpose is to provide that, young queer or lesbian, trans player out there, a social, safe refuge where they don't have to reinvent the wheel, and test for safety, and all that kind of stuff...But at the end of the day, it's all about providing that one more person who needs that safe space experience.

His group primarily meets online and has a created a space that allows people to be open about all aspect of their lives; additionally, this safe space allows people to have gaming experiences that are free from homophobic harassment.

Peter's group also strives to create a "safe space", he says, “...well, we try to provide the safest space as we can. We realise it can't be possible $100 \%$ of the time, but it's something we strive for." It is interesting to note that although his group wants to create a safer space for its members, he knows that it may not be entirely possibly. The usage of the word "safest" does imply this and it's ethically important that groups state this. Creation of a "safe space" is difficult because of the various intersecting identities that members have and where they may be triggered. Further, the level of coping with these triggers varies among individuals and how these triggers can impact an experience.

Tom's opinion about safe space is also important to his group. He describes this as “.... space where people won't belittle them for their choice of game or whatever it allows them to be themselves." Again, similar to the previous participants, Tom's group also strives to create a space where people will be safe to play games that may have a reputation of being unsafe. First person shooter games are often said to be unsafe spaces (Shaw, 2013), however there are LGBTQ players/gaymers that do play. Gaymer groups that create safer spaces for these members allow them to play safely and to feel supported. 
All three participants advocating and creating these safer spaces for members of the gaymer groups, demonstrates the importance of these spaces. Linking this back to Lefebvre's (2009) concept of space and creating it to be their own (p.38), gaymer groups create these safer spaces. These spaces are queer because they are no longer seen to be dominated by what is deemed to be a heteronormative space. Queering the space is linked with creating safer spaces because when one "queers" a space they make it acceptable or comfortable for a person to be open about their identities. What this looks like is a space that will not tolerate homophobic harassment and where players play games together hopefully in a non-judgemental way.

Advocating for these safer spaces for all players has to happen to ensure these spaces are created. Orion talked about how his group had to take some legal action against a gaming company for some homophobic actions:

a lawsuit... (was brought up against) a (gaming company,) who runs an (online game,) because they were prohibiting a trans woman from asking for ....(or organizing) members, (who were) trans-friendly or LGBT-friendly members in basic/general chat ... and she was shut down, and squelched, and silenced...

It was through legal action that change was made; without this legal action, the creation of a safer space through in game organizing would not have been possible. However, Orion does say that things have changed:

I would say looking back over the last 14 years... I mean, I'd like to say it's gotten better. I think what it's gotten is more chill. There are who are pro-LGBT gamers and understand who maybe not directly part of the community, but are allies, advocates... 
Through the creation of ally-ship and the building of bridges to those who are trying to understand the importance of diversity in gaming, things have changed. The discourse of the gamer being primarily heterosexual and having only heteronormative gaming narratives has changed.

In sum, creating safe or safer spaces is one goal that gaymer groups have, especially considering the history of harassment that many LGBTQ players/gaymers have experienced. Through queer space, safe space can be created. However, gaymer groups also understand that no space can truly be "safe" but they can be "safer" because of the various intersecting identities that make up a person and where multiple sites of oppression can be experienced. Through safe/safer spaces some advocacy changes can be made as noted in one example above; however, the main reason for these spaces is that members of gaymer groups can feel like they can be open and be themselves without fear of backlash.

\section{Politics and change within the gaming/geek community through queering space}

Political engagement within groups varied by participant and gaymer group. Peter said this about his group: “...we have such a diverse group of people that they have their own opinions that we don't have any official political stances." Similarly, Tom indicated: "we try and minimize how politics interact with the group but there is always something that directly affects us such as LGBT rights, trans rights, trans recognition and things of that nature...". However, unlike Peter and Tom's, Orion's group was willing to engage in political action because of the current political climate where his group was primarily based. Orion said, “... protest is Pride, 'cause it's scary, you know, it's pretty f'ing scary right now...”. 
The leaders/organizers of the gaymer groups seem to work from a bottom-up approach. Thus, if leaders/organizers may want to engage in political action but the majority of the membership does not, then the leader/organizer will respect the will of the membership. Additionally, it also looks like many gaymer leader/organizers may feel uncomfortable bringing up politics in gaymer groups because politics can be viewed as a divisive force more than a way of uniting or creating learning dialogues.

In addition to (or in lieu of) direct political engagement, queering space also happens as a form of resistance. The gaming community is interesting because it relies on the creation of games from developers for it to exist. As stated in the literature review, game developers create games that usually reflect the developer or a targeted audience; and as such, gaming narratives are primarily heteronormative. Shaw (2012), brings this up in her arguments on who identifies as a gamer or not their reasons for this. She argues that gaming companies do not reflect the diversity of their market because of who is assumed to be a gamer. Groups have tried to make changes to this narrative of heteronormativity through campaigning and advocating for diversity in games. As an example, Orion's group had to advocate through legal means to ensure LGBTQ groups within the game were legitimatized and would not be banned for being seen as "obscene" because of the usage of the words "Gay, Lesbian, Transsexual, Bisexual, and Queer." Orion discusses what happened:

people were saying it's vulgar or whatever. And so, we have this dance with (gaming company) over the years, back and forth, about them cancelling our (group) name. And of course, our ... members (are) very passionate about that because it's our unique identifier. When little, gay player at level two is running around and they see (the group), they like 
say, "oh, I saw (this group) in that other game ten, five years ago"...I guess, that we used to be readily identifiable. And, we've had some discussion with (the game company) that have gotten a little bit heated sometimes. And we recently had a phone conference with them, in which we sort of explained ourselves, and they shared their concerns, and we got a passage, we got a free pass to use (the name of the group), and they won't turn it off any more, which is cool."

The video game company used to ban these words because they wanted to avoid dealing with LGBTQ players that play their games. However, this is a form of silencing and not dealing with the homophobia/queerphobia that occurs when LGBTQ players become or want to become visible. When visibility of LGBTQ players/gaymers occurs then harassment may occur, as noted in the study by Pulos (2013) and as experienced by Orion's group.

Similarly, Peter's group is also creating safer spaces within the gaming/geek community through organizing diversity safe rooms at gamer and geek culture events or gatherings. Diversity or safer spaces rooms are usually part of a gaming/geek conventions that act as a means for attendees of these conventions to learn about the diversity within the gaming/geek communities. Peter talks about how this came to be:

... we've been involved in the (diversity room) since they created it at (this convention) ... where we participated as a group; I think at times we were the only kind of group that was in there. So, it kind of gave us an idea of ... how they're running... But this year, changes in (the convention) staffing ... eliminated .... the use of non-paid volunteers... So, they didn't have anybody to run the lounge so they .... offered it to our group... 
Through organizing this section of a popular convention, Peter's group is taking an initiative in creating bridges and dialogue with non-LGBTQ gamers/geek attendees. This is a form of advocacy that is visible and offers people a chance to learn about the diversity within gaming culture. This type of organizing also challenges perceived assumptions that gamers are a homogenous group. This also takes us back to queer space in a place that is seen as heteronormative; organizing this space queers it in a way that is educational and creates dialogue and understanding through learning and unlearning. Tom also talks about how his group has also been creating changes within the community: “...we do marching in the pride parade, we offer a booth ... We do the same things at convention...". Through participating at their local pride parade and doing outreach at gaming/geek conventions, they also outreach to LGBTQ players who may not know that their group exits. Additionally, they are also creating a bridge and dialogue with non-LGBTQ players so that they discuss and challenge who is (or can be) a gamer. Through visibility and queering dominant space, change can happen.

Looking at all three groups and their methods of creating change highlights the importance of queering the spaces that they are in. It is through these efforts that changes happen because of the room to create dialogue with other gamers; and more importantly challenging the dominant group's perception of who can be a "gamer." This queering of space can make those who do not identify as LGBTQ uncomfortable because they may have been accused of "homophobia". In short, the changes that are happening to challenge homophobia in gaming are being done by these gaymer groups through education and dialogue building; and this is possible through queering spaces in gaming. These types of resistance efforts and 
community building have several implications for practice and research which I discuss in the following chapter. 


\section{CHAPTER 5. IMPLICATIONS \& CONCLUSION}

Gaymer groups are still relatively new communities; and through this research paper I aimed to provide a small glimpse of the impact that these group are having on combating homophobia and heteronormativity in the gaming world. Through the interviewing process of LGBTQ gaymer leaders/organizers I was as able to show the impact that creating queer spaces in gaming has had on LGBTQ players/gaymers. Through their narratives, we can see that these gaymer groups do have a positive impact in helping create safer gaming spaces. This is primarily done thorough the creation of social relationships through these groups. The feelings of isolation and the development of comradery help LGBTQ players/gaymers develop friendships that are based around gaming and sexuality. The idea of "strength in numbers" applies here as resistance to the harassment that many LGBTQ players/gaymers have experienced in gaming spaces, which is counteracted through these friendships. These friendships create supports for people who may experience harassment in games or who may be experiencing mental health issues.

\section{Implications for Practice}

With the creation of these gaymer groups a new community does emerge. LGBTQ players/gaymers, are creating their own community that is specific to gaming. In this way, community can exist in both the virtual and physical worlds. This community is an example of coming together for a common cause through a passion for gaming. Social work can learn from gaming communities that resistance to oppression can occur in communities that are often overlooked because they do not reflect mainstream views of what is deemed as an oppressed community. As opposed to viewing space as only geographical, social work needs to look towards online communities that can develop. 
Through queering gaming spaces and making them safer for LGBTQ players, gaymer groups have had a positive impact through the creation of social relationships and also through becoming more visible in the community at large. For one group, it was being able to make changes in the gaming world through lobbying and advocating against the silencing of LGBTQ organizing in games. Additionally, for city specific gaymer groups, they have become visible leaders in their communities. One group queered space in a gaming/geek convention, while another made their cause visible in a pride parade and thus making it known that they exist. These actions are forms of queering space in places that are not always targeted towards LGBTQ communities. Through social work we can see the importance of social space and how creating these new social spaces through lenses such as queer theory are acts of creating safer spaces and challenging patriarchy and heteronormativity.

Likewise, the creation of "safe/safer" spaces is another theme that was brought up and one that was common among all the gaymer group leader/organizer participants. Striving to create these safe/safer spaces is important because this requires queering space so people can feel safe. These safer/safe spaces are political because they acknowledge that there are problems of homophobia in the gaming worlds. If these spaces are being created, this reflects the fact that someone is feeling unsafe and getting hurt. Creating safer spaces does two things, one is makes members who are often viewed as other safer and welcomed and secondly it politically challenges systems that are homophobic and heteronormative. For social work, we again see the importance of doing community work with groups in various aspects of society. Sometimes these group will be in spaces that can be seen as "other" (e.g. online communities). 


\section{Implications for Research}

In addition to implications for practice, this study holds several directions for future research. The topic of gaymer groups is relatively new and there are not many academic research on this topic. This proved to be a challenge because much academic literature explored harassment experiences of women gamers. Additionally, research an LGBTQ gaming was also limited to a handful of studies as noted in the literature review. A more diverse body of academic research would be important to better understand the issues at the heart of this study. My hope is that more research will be conducted on this topic; judging from my interviews, there are many areas left to explore.

More research could be conducted on gaming companies and how they have changed their marketing and game development. Specifically, research on who game companies are hiring to design and create games can show if change is happening. Additionally, researching gaming companies and the games that are produced, their narratives and target audience could also allow us to see if diverse perspectives are represented. Research can also be conducted on game designers themselves to see if there are more women, men, and LGBTQ game designers. Research can study game design schools to see who the current and past students are and how reflective they are of the diversity of gamers.

A related area of research is looking at indie game designers. Indie games are games that are being created by non-corporate gaming companies and primarily lead by independent game developers. Indie games are typically non-mainstream and are created by game designers who want more freedom in the games that the create. Examining the demographics of who these indies game designers are and what type of games are being developed can further inform us if 
there is more diversity in gaming. This would demonstrate whether counter gaming narratives are being developed.

Moreover, it would be important to explore gaymer groups that are region/city specific and those that primarily meet online. Although both types of groups do have many similar goals, I have also noticed vast differences between them; the region/city focused gaymer groups may start off online but once they meet and organize outside of the cyber world they become integrated into their city community. In contrast, the online gaymer groups have memberships that come from all over and in a sense, are a global group that has members that reside in all parts of the world. It would be interesting to see how this changes the supports provided by this group; and how an online focused gaymer group would work on issues that are non-western and non-North American. Indeed, the study looked at three gaymer groups there were North America based, and it would be interesting to see the differences between the impacts and supports of various gaymer groups from around the world that are region/city specific. This type of research would look at the cultural context of where the gaymer group is located and explore culturally differences. Additionally, another study could just focus on Canadian gaymer groups. Canada is regionally different from province to province and such research would provide insight into the impacts these groups have in various Canadian cities.

A focus on the type of games played in each group would be interesting to look at instead of lumping them together. The regional/city gaymer groups play both video and board games and there are difference between the two types of gamers. Board games require people to play face to face and are seen to be more socially focused, whereas video games can be played solo and players can choose to play with others if they use the internet to connect with other players. 
Looking specifically if board gaymers are different from those who play video games would further explore the impact gaymer groups have.

The study conducted also was from a perspective from three gay identified males. Their perceptions may not reflect the full spectrum of LGBTQ gaymers. Female identified gaymers and trans gaymers may have a vastly different experience. Looking at their experience may give a different perspective because they would be seeing it from the lenses of sexuality, gender, and gender identity. The literature review has shown that women are more likely to experience harassment and sexism from other gamers. Having sexuality and gender lenses would be important in understanding how lesbian/queer women-identified players experience their game play and how it impacts them. Additionally, we can also look at the impact gaymer groups have on lesbian/queer women-identified players.

Trans identified players' perspective would also need to be studied separately because sexuality and gender identity are two different lenses. Looking at trans identified players' experiences in the gaming world and their experiences in gaymer groups can also provide more insight to see if gaymer groups are places of support for trans players or if they also experience oppression from the gaming world and possibly within gaymer groups. It is important to acknowledge as many perspectives as possible from LGBTQ gaymers because they are not a homogenous group but instead have various intersecting identities.

The topic of mental health and gaming was brought up by the participants. But since this study was focused on LGBTQ sexuality, another study could look at the links between sexuality, mental health and gaming. There seems to be a relationship between these elements of experience and a focused study can see if this is true. 
Overall, more research should be conducted on gaymer groups; interviewing more leaders/organizers, and obtaining data from the members themselves would give a better understanding of the impacts of gaymer groups and the spaces they create. The understanding of social space creation through online communities is relevant to social work practice because this could be seen as an evolution of community development. With the usage of the internet, gaymer communities could be created as a response to harassment and isolation felt due to marginalization. Community social work needs to further accept and be open minded that these communities are important to people and that they do create social supports.

Finally, social work can learn how these online communities' resistance to oppression demonstrates resilience and view the spaces being created as worthwhile examples of community building. Studying these types of communities will give us a better understanding of their impact on society. As I have noted throughout this MRP, this topic is still relatively new and hopefully social work can play a role in ensuring that more research will be conducted to see long term impact and longevity of gaymer communities. 


\section{APPENDICES}

\section{Appendix A}

To whom it may concem,

My name is Samson Romero, and I am a Master of Social Work student at Ryerson University's School of Social Work. I am currently completing a major research paper on LGBTQ gaming groups and how the creation of these groups helps creates safer spaces for LGBTQ

players/gaymers in both the virtual world and in the real world. I am inviting you to participate in this study yourself or to pass this along on to anyone you know who may wish to participate in this study.

I am seeking volunteers to interview who are at least 18 year of age and identify as being the community leader or organizer of an LGBTQ gaming group; this can be a group online or in the physical community. The group itself must be LGBTQ focused and have that reflected in their mission statement or by-laws. In addition, groups' must have been active for a least one year and are still currently active.

The purpose of this study is to explore how creating "queer spaces" has impacted the gaming culture in relation to the harassment LGBTQ players/gaymers have been experiencing. I will also be examining how the creation of these groups have had in developing an LGBTQ gaming community and seeing the effects this has had on LGBTQ players/gaymers.

The interviews will be conducted either in-person or through skype in either video or audio. The interview should take no longer than 2 hours. Some questions asked will be around what your group does and the history of your group.

Participation in this research study is strictly voluntary. Additionally, if you do chose to participate your involvement will not impact any current or future professional relationship you may have with me, even if you do choose to stop/withdraw from the study. This study is not associated with my work with Toronto Gaymers. I appreciate you taking the time to read this and pass it on if you so choose.

If you are interested in the study or obtaining more information about the study, please feel free to contact me at the email provided below. Thank you in advance for your time and consideration.

Sincerely,

Samson Romero, BSW, RSW

School of Social Work at Ryerson University samson.romero@ryerson.ca 


\section{Appendix B}

\section{Interview Guide}

1) Can you tell me about your group?

a. Inquire about history

b. Does it meet online or outside (or both)

c. What activities or services does the group do or provide?

d. Is there a political component to it?

2) Has your group experienced any resistance?

a. Any harassment that was directed towards your group from other gaming or geek groups?

i. From in person

ii. From online

b. Any negative experience from the LGBTQ communities?

c. Have members reported any harassment as a reason for joning?

3) Can you tell me from your experience as a leader/organizer the impact your group has had on the members?

a. Why do they keep coming back/participating?

b. What are some of the positive feedback you have received?

c. What are some of the negative feedback you have received?

4) In your experience as an organizer/leader what are some challenges that you have encountered?

a. Any internal group tensions

b. Any problems or themes they are noticing with their members

c. Is anyone missing or left out if so why?

d. How are trans identified members included

5) What is your group's relationship with non-LGBTQ gaming groups?

a. How was their group received from other non-LGBTQ gaming groups?

b. Any attempts at building relationships, if so how?

6) Does your group have a relationship to the non-gaming LGBTQ community?

a. Ask about participating in PRIDE

b. Do they do outreach outside of gaming/geek social circles

c. If no, ask why? If yes, inquire how?

7) What is your group's long term goals within the next 2-3 years?

a. Working on any projects?

b. What is the long term purpose of this group? 


\title{
Appendix C
}

\section{Ryerson University: Consent Agreement}

You are being invited to participate in a research study. Please read this consent form so that you understand what your participation will involve. Before you consent to participate, please ask any questions to be sure you understand what your participation will involve.

Project Title: Queering Space: LGBTQ* Gaming as a form of resistance and community development

\section{INVESTIGATORS:}

I, Samson Romero, am a graduate student and am the principal investigator of this study. This research is being conducted under the supervision of Dr. Samantha Wehbi in order to fulfill the requirements of my Master's degree.

\author{
Samson Romero BSW RSW \\ School of Social Work at Ryerson University \\ samson.romero@,ryerson.ca
}

\author{
Samantha Wehbi, MSW, PhD, MFA \\ School of Social Work, Faculty of Social Work at Ryerson University \\ 4169795000 ext. 6221 \\ swehbi@ryerson.ca
}

If you have any questions or concerns about the research, please feel free to contact myself at the email provided.

Purpose of the Study: The purpose of this study is to explore how creating "queer spaces" has impacted the gaming culture in relation to the harassment LGBTQ players/gaymers have been experiencing. I will also be examining how the creation of these groups have had in developing an LGBTQ gaming community and seeing the effects this community has had on LGBTQ players/gaymers.

What Participation Means: Your participation in this study will consist of either an skype interview (audio/video). If you agree to participate, I will be asking you questions about your experiencing organizing and coordinating an LGBTQ gaming group.

- I will be doing a one on one skype interview with you

- The research is superficially looking at the impact your group has had on combating homophobic harassment and effect it has had on your members. 
- The interview should take no longer than 2 hours.

- Participants can expect questions such as:

○ Tell me the reasons why your group was formed?

- Has your group experienced any negative backlash?

$\circ$ What are you goals for the group?

Potential Benefits: I am hoping that this study will give you as participants the ability to reflect on your group's accomplishments. Although, I cannot guarantee that you may gain anything from this interview

Risks or Discomforts: The risks to you is low, however some questions may trigger emotional responses, you can take a break, skip questions and not finish the interview.

Confidentiality: This interview will be kept strictly confidential and all identifying information will be omitted from the transcripts. The researcher will ensure the location the skype interview is being conducted in will be private and secure. Excerpts of this interview may be made part of research reports, presentations or articles, but under no circumstances will your name or any identifying characteristics be included in any way. Audi/Video recordings will be password protected. Once the recordings have been transcribed, they will be destroyed. Transcripts will not have your name or identifying information on them; pseudonyms will be assigned to participants in order to ensure confidentiality. All of the necessary steps will be taken to ensure the participant's confidentiality is maintained throughout the research process to minimize risks.

Costs and/or Compensation for Participation: I am providing a $\$ 10.00$ (US) gift card to either Steam or Think Geek as compensation for your time.

Other cost of participation including data plans and parking and gas will not be reimbursed.

Voluntary Nature of Participation: Participation in this study is voluntary. Your choice of whether or not to participate will not influence your future relations with me, or with Ryerson University. If you decide to participate, you are free to withdraw your consent and to stop your participation at any time without any consequence to you; you would still be entitled to the reimbursements discussed above. At any particular point in the study, you may refuse to answer any particular question or stop participation altogether.

Questions about the Study: If you have any questions about the research now, please ask. If you have questions later about the research, you may contact:

Samson Romero, BSW RSW

School of Social Work, Ryerson University

samson.romero@ryerson.ca 
Samantha Wehbi, MSW, PhD

School of Social Work, Faculty of Social Work at Ryerson University

4169795000 ext. 6221

swehbi@,ryerson.ca

If you have questions regarding your rights as a human subject and participant in this study, you may contact the Ryerson University Research Ethics Board for information. This study has been reviewed by the Ryerson University Research Ethics Board. If you have questions regarding your rights as a participant in this study please contact:

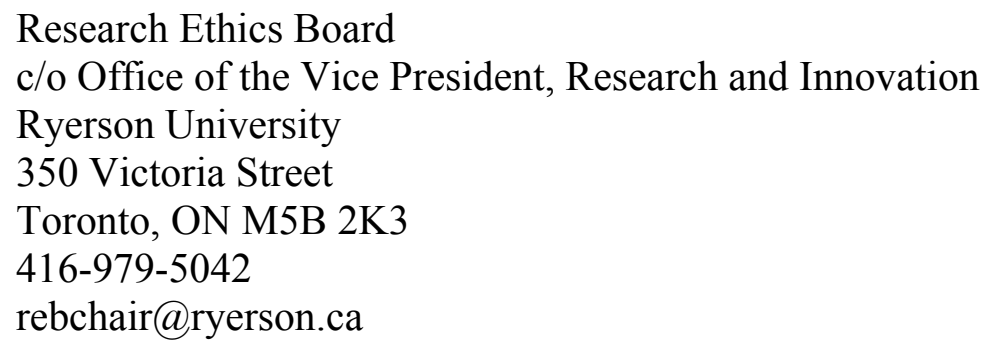

Research Ethics Board c/o Office of the Vice President, Research and Innovation Ryerson University 350 Victoria Street

Toronto, ON M5B 2K3

416-979-5042

rebchair@ryerson.ca

Project Title: Queering Space: LGBTQ* Gaming as a form of resistance and community development

Agreement:

Your signature below indicates that you have read the information in this agreement and have had a chance to ask any questions you have about the study. Your signature also indicates that you agree to be in the study and have been told that you can change your mind and withdraw your consent to participate at any time. You have been given a copy of this agreement. You have been told that by signing this consent agreement you are not giving up any of your legal rights.

\begin{tabular}{lll}
\hline Name of Participant (Please Print) & \\
Signature of Participant & & Date \\
\hline Signature of Investigator & Date
\end{tabular}

I agree to be audio recorded for the purposes of this study. I understand how these recordings will be stored and destroyed.

Signature of Participant
Date 


\section{Appendix D}

\section{Research Ryerson Ethics Board University}

To: Samson Romero Social Work

Re: REB 2017-049: Queering Space: LGBTQ* Gaming as a form of Resistance and community development

Date: March 27, 2017

\section{Dear Samson Romero,}

The review of your protocol REB File REB 2017-049 is now complete. The project has been approved for a one year period. Please note that before proceeding with your project, compliance with other required University approvals/certifications, institutional requirements, or governmental authorizations may be required.

This approval may be extended after one year upon request. Please be advised that if the project is not renewed, approval will expire and no more research involving humans may take place. If this is a funded project, access to research funds may also be affected.

Please note that REB approval policies require that you adhere strictly to the protocol as last reviewed by the REB and that any modifications must be approved by the Board before they can be implemented. Adverse or unexpected events must be reported to the REB as soon as possible with an indication from the Principal Investigator as to how, in the view of the Principal Investigator, these events affect the continuation of the protocol.

Finally, if research subjects are in the care of a health facility, at a school, or other institution or community organization, it is the responsibility of the Principal Investigator to ensure that the ethical guidelines and approvals of those facilities or institutions are obtained and filed with the REB prior to the initiation of any research.

Please quote your REB file number (REB 2017-049) on future correspondence.

Congratulations and best of luck in conducting your research.

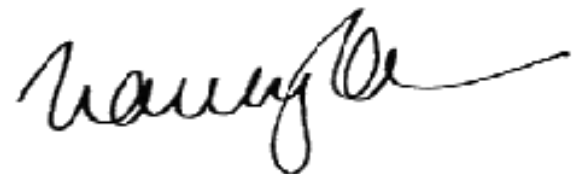

Dr. Nancy Walton, $\mathrm{PhD}$

(A) Co-Chair

Ryerson Research Ethics Board

416-212-4952

nwalton@ryerson.ca

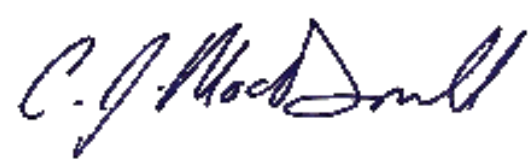

Dr. Chris Macdonald, $\mathrm{PhD}$

(A) Co-Chair

Ryerson Research Ethics Board

416-979-5000 ext. 6903

chris.macdonald@ryerson.ca 


\section{REFERENCE LIST}

Baskin, C. (2011). Strong Helpers teachings: the value of Indigenous knowledges in the helping professions. Toronto: Canadian Scholars Press.

Braithwaite, A. (2014). "Seriously, get out": Feminists on the forums and the War(craft) on women. New Media \& Society, 16(5), 703-718. http://doi.org/10.1177/1461444813489503

Cilauro, R. (2015). Community building through a public library Minecraft Gaming Day. The Australian Library Journal, 64(2), 87-93. http://doi.org/10.1080/00049670.2015.1015209

Chaskin, R J. (2013). Theories of Community. In Weil, M., Reisch, M., \& Ohmer, M. L The handbook of community practice. (pp.105 - 122) Thousand Oaks, CA: SAGE Publications.

Creswell, J. W., \& Poth, C. N. (2013). Qualitative inquiry \& research design: choosing among five approaches. Los Angeles: SAGE.

Cruea, M., \& Park, S.-Y. (2012). Gender Disparity in Video Game Usage: A Third-Person Perception-Based Explanation. Media Psychology, 15(1), 44-67. http://doi.org/10.1080/15213269.2011.648861

Eklund, L. (2011). Doing gender in cyberspace: The performance of gender by female World of Warcraft players. Convergence: The International Journal of Research into New Media Technologies, 17(3), 323-342. http://doi.org/10.1177/1354856511406472 
Evans, B., \& Janish, E. (2015). \#INEEDDIVERSEGAMES: How the Queer Backlash to GameGate Enables Nonbinary Coalitions. QED: A Journal in GLBTQ Worldmaking, 2(2), $125-150$.

Fook, J. (2012). Social work: a critical approach to practice. London: SAGE Publications Ltd.

Ghuman, D., \& Griffiths, M. (2012). A Cross-Genre Study of Online Gaming. International Journal of Cyber Behavior, Psychology and Learning, 2(1), 13-29. http://doi.org/10.4018/ijcbpl.2012010102

Hanckel, B., \& Morris, A. (2014). Finding community and contesting heteronormativity: Queer young people's engagement in an Australian online community. Journal of Youth Studies, 17(7), 872-886. http://doi.org/10.1080/13676261.2013.878792

Hsiao, C. C., \& Chiou, J. S. (2012). The effects of a player's network centrality on resource accessibility, game enjoyment, and continuance intention: A study on online gaming communities. Electronic Commerce Research and Applications, 11(1), 75-84. http://doi.org/10.1016/j.elerap.2011.10.001

Hussain, Z., \& Griffiths, M. D. (2014). A Qualitative Analysis of Online Gaming: International Journal of Cyber Behavior, Psychology and Learning, 4(June), 41-57. http://doi.org/10.4018/ijcbpl.2014040104 
Jia, A. L., Shen, S., Bovenkamp, R. Van De, Iosup, A., Kuipers, F., \& Epema, D. H. J. (2015). Socializing by Gaming. ACM Transactions on Knowledge Discovery from Data, 10(2), 129. http://doi.org/10.1145/2736698

Kaye, L. K., \& Pennington, C. R. (2016). "Girls can't play”: The effects of stereotype threat on females' gaming performance. Computers in Human Behavior, 59, 202-209. http://doi.org/10.1016/j.chb.2016.02.020

Lauteria, E. W. (2012). Ga(y)mer theory: Queer modding as resistance. Reconstruction: Studies in Contemporary Culture, 12(2). Retrieved from http://reconstruction.eserver.org/Issues/122/Lauteria_Evan.shtml

Lefebvre, H., \& Nicholson-Smith, D. (2009). The production of space. Malden, MA: Blackwell.

Lee, J.E. R. (2014). Does virtual diversity matter?: Effects of avatar-based diversity representation on willingness to express offline racial identity and avatar customization. Computers in Human Behavior, 36, 190-197. http://doi.org/10.1016/j.chb.2014.03.040

Lessard, D. (2013). Queering the Urban, Queering Critical Ethnography. In O'Mara, K., \& Morrish, L. Queering paradigms III: queer impact and practices (pp.259 - 278) Bern, Switzerland: Peter Lang. 
Lewis, E. S. (2013). Queer Subversion or Heteronormative Reinforcement? Linguistic Performativity in the Identity Constructions of a Young, Bisexual- Identified Brazilian LGBY Activist. In O'Mara, K., \& Morrish, L. Queering paradigms III: queer impact and practices (pp.201-236) Bern, Switzerland: Peter Lang.

Madison, D. S. (2005). Critical ethnography: method, ethics, and performance. Place of publication not identified: Sage.

McCaffrey, E. (2013). From Homographies of Invisibility to Hypervisibility: Queering and DeQueering City Center Space. In O'Mara, K., \& Morrish, L. Queering paradigms III: queer impact and practices (pp.33-61) Bern, Switzerland: Peter Lang.

McNeil, C. (2016, August 26). League of Legends: Fans taking over sold-out ACC to watch world's most popular video game TheMetro. Retrieved from http://www.metronews.ca

Pulos, A. (2013). Confronting Heteronormativity in Online Games: A Critical Discourse Analysis of LGBTQ Sexuality in World of Warcraft. Games and Culture, 8(2), 77-97. http://doi.org/10.1177/1555412013478688

Salter, A., \& Blodgett, B. (2015). Hypermasculinity \& Dickwolves: The Contentious Role of Women in the New Gaming Public. Journal of Broadcasting \& Electronic Media, 56(3), 401-416. http://doi.org/10.1080/08838151.2012.705199 
Schmieder, C. (2008). World of Maskcraft vs. World of Queercraft? Communication, sex and gender in the online role-playing game World of Warcraft. Journal of Gaming and Virtual Worlds, 1(1), 5-21. http://doi.org/10.1386/jgvw.1.1.5/1

Shaw, A. (2009). Putting the Gay in Games. Games and Culture, 4(3), 228-253. http://doi.org/10.1177/1555412009339729

Shaw, A. (2012). Do you identify as a gamer? Gender, race, sexuality, and gamer identity. New Media \& Society, 14(1), 28-44. http://doi.org/10.1177/1461444811410394

Teng, C.-I., Tseng, F.-C., Chen, Y.-S., \& Wu, S. (2012). Online gaming misbehaviours and their adverse impact on other gamers. Online Information Review, 36, 342-358. http://doi.org/10.1108/14684521211241387

Todd, C. (2012). "Troubling" gender in virtual gaming spaces. New Zealand Geographer, 68(2), 101-110. http://doi.org/10.1111/j.1745-7939.2012.01227.x

Who we are. (2017, October 29). Retrieved from http://www.torontogaymers.ca 